\title{
ENRAIZAMENTO DE MINIESTACAS DE Croton urucurana Baill. EM FUNÇÃO DO VOLUME DO TUBETE E POSIÇÃO DO RAMO NA PLANTA MATRIZ
}

\author{
XAVIER, Maxuel Fellipe Nunes ${ }^{1}$ \\ FLORES, Paulo Ricardo Lima ${ }^{1}$ \\ FLORIANO, Solange Aparecida ${ }^{2}$ \\ CAMPOS, Arnaldo Gonçalves de ${ }^{3}$ \\ PIMENTA, Alex Caetano ${ }^{3}$ \\ ARAÚJO, Charles de ${ }^{3}$ \\ COELHO, Maria de Fátima Barbosa ${ }^{4}$
}

\begin{abstract}
RESUMO: No presente trabalho objetivou-se avaliar o enraizamento de miniestacas de Croton urucurana Baill., confeccionadas a partir de diferentes posições do ramo da planta matriz e diferentes recipientes. As miniestacas utilizadas foram coletadas a partir de minicepas, oriundas de propagação seminífera. Os tratamentos foram arranjados em esquema fatorial $2 \times 3$, sendo dois tipos de recipientes $\left(55 \mathrm{~cm}^{3}\right.$ e $\left.110 \mathrm{~cm}^{3}\right)$ e três tipos de miniestacas em relação a posição no ramo da planta matriz (apicais, semilenhosas e lenhosas). O delineamento utilizado foi o de blocos ao acaso, com 4 repetições. O experimento foi instalado em casa de vegetação, e após 25 dias foi transferido para casa de sombra, onde permaneceu por 10 dias, totalizando 35 dias. Avaliou-se na saída da casa de vegetação e de sombra as variáveis, em porcentagem: enraizamento, sobrevivência - considerando as miniestacas vivas e não enraizadas, brotação e manutenção de folhas. Nas duas avaliações houve interação significativa para porcentagem de manutenção de folhas, sendo constatado o efeito significativo do recipiente na variável sobrevivência e do tipo de miniestaca no enraizamento, sobrevivência e brotação. Quanto ao enraizamento, em ambas avaliações, observou-se as miniestacas de origem apical resultam em melhor enraizamento quando comparadas às lenhosas, embora não tenha diferido estatisticamente das semilenhosas. Diante dos resultados obtidos, conclui-se que: confeccionar miniestacas das partes apical e semilenhosa do ramo da planta matriz otimiza o enraizamento; podem ser utilizados recipientes de $55 \mathrm{~cm}^{3}$ ou de $110 \mathrm{~cm}^{3}$ para a propagação vegetativa de Croton urucurana por miniestaquia.
\end{abstract}

Palavras-chave: Sangra-d'água. Propagação. Miniestaquia. Minicepa.

\section{ROOTING OF MINI STACKS OF Croton urucurana Baill. IN FUNCTION OF THE TUBET VOLUME AND BRANCH POSITION IN THE MATRIX PLANT}

SUMMARY: In the present work, the objective is to evaluate or reduce the mini-cuttings of Croton urucurana Baill., Made from different positions of the plant branch and different recipients. As the used mini-cuttings were collected from mini-stumps, originating from the propagation of seminars. The procedures were organized in a $2 \times 3$ factorial scheme, with two types of containers $\left(55 \mathrm{~cm}^{3}\right.$ and $\left.110 \mathrm{~cm}^{3}\right)$ and three types of minicuttings in relation to the position in the plant branch (apical, semi-woody and woody). The design used was randomized blocks, with 4 replications. The experiment was installed in the greenhouse and after 25 days it was transferred to the shade house, where it remained for 10 days, totaling 35 days. Prohibited when leaving the greenhouse and shade as variables, in percentage: rooting, savings - considering live and unrooted mini-cuttings, budding and leaf maintenance. In both statistics there was a significant interaction for the percentage of leaf maintenance, with the container with variable variables and the type of minicutting in rooting, survival and sprouting being found or with significant effect. As for rooting, in estimated embassies, if the mini-cuttings of apical origin result in better rooting when compared to the woody ones, although they did not differ statistically from the semi-wood ones. In view of the results obtained, we conclude that: mini-cuttings made from apical and semi-wood parts of the branch of the optimized matrix plant or rooting; $55 \mathrm{~cm}^{3}$ or $110 \mathrm{~cm}^{3}$ containers can be used for vegetative propagation of Croton urucurana by mini-cutting.

\footnotetext{
${ }^{1}$ ORCID id - http://orcid.org/0000-0003-0822-4992 - Graduando em Agronomia, Instituto Federal de Educação, Ciência e Tecnologia de Mato Grosso/Campus São Vicente, Campo Verde-MT, Brasil. maxuelfellipe90@gmail.com

${ }^{2}$ Estudante do Ensino Médio, Escola Estadual Gustavo Dutra, São Vicente da Serra-MT, Brasil.

${ }^{3}$ Doutor, Professor do Instituto Federal de Educação, Ciência e Tecnologia de Mato Grosso/Campus São Vicente, Campo Verde-MT, Brasil.

${ }^{4}$ Doutora, Professora do Programa de Pós-Graduação em Agricultura Tropical da Universidade Federal de Mato Grosso/Campus Cuiabá, Cuiabá-MT, Brasil.
}

Nucleus, v.17, n.2, out.2020 
Keywords: Sangra-d'água. Propagation. Mini cuttings. Minicep.

\section{INTRODUÇÃO}

A família Euphorbiaceae possui distribuição predominantemente pantropical, incluindo cerca de 300 gêneros e 6.000 espécies. No Brasil ocorrem cerca de 60 gêneros e 900 espécies, representando uma das principais famílias da flora brasileira e uma das mais complexas do ponto de vista taxonômico. Elas estão entre as famílias mais comuns nas formações naturais brasileiras. O gênero Croton é particularmente comum em quase todos os ecossistemas brasileiros, com destaque para C. urucurana Baill, típico de florestas ciliares (SOUZA; LORENZI, 2012).

Croton urucurana Baill, popularmente conhecida como sangra-d’água, é uma planta arbórea e pioneira com grande adaptabilidade para ambientes úmidos e brejosos (LORENZI, 2016) e, por isso, é de grande importância para reflorestamentos e para a proteção de espécies tardias, devido ao sombreamento que ela produz, sendo especialmente indicada para recomposição de matas ciliares, e para reflorestamento em regiões de cerradão (SCALON et al., 2008). Além disso, trata-se de uma espécie de uso etnofarmacológico, pois contém substâncias com atividades anti-hemorrágica, anti-inflamatória, antisséptica, antiviral e cicatrizante (SOLDERA; ZANELLA; FRASSON, 2010). É utilizada tanto na medicina tradicional como na farmacológica (SODRÉ; SILVA, 2015; CAMILLO; VIEIRA, 2016), e tem elevado potencial melífero (LORENZI, 2016).

Para utilização em reflorestamentos é necessária a produção de mudas utilizando diferentes técnicas da propagação vegetativa. Nesse contexto, a miniestaquia é uma alternativa que vem sendo bastante aplicada na propagação de espécies florestais (ALFENAS et al., 2009). Ela consiste em miniestacas cujo comprimento pode variar de 3 a $5 \mathrm{~cm}$ e que são confeccionadas a partir de brotações de plantas propagadas pelo método de estaquia convencional (WENDLING; FERRARI; GROSSI, 2002) ou de plantas matrizes oriundas de sementes (XAVIER; WENDLING; SILVA, 2013).

$\mathrm{Na}$ propagação vegetativa de espécies lenhosas por enraizamento adventício, à estaca caulinar tem sido o tipo de propágulo mais empregado (XAVIER; WENDLING; SILVA, 2013). A consistência dos tecidos e a posição do ramo dos quais os propágulos são retirados podem acarretar respostas diferenciadas no processo de enraizamento adventício (FACHINELLO; HOFFMANN; NACHTIGAL, 2005). As miniestacas intermediárias e lenhosas, denominadas como semilenhosas e lenhosas, respectivamente, acarretam de forma mais pronunciada a perda de vigor, a lignificação dos tecidos e os efeitos negativos do envelhecimento ontogenético (WENDLING; XAVIER, 2001). Nesse sentido, em viveiros florestais estabelece-se o uso de 
miniestacas apicais, por formarem raízes com maior facilidade, em virtude de possuírem os meristemas, os quais são locais de síntese natural de auxinas nas plantas (HARTMANN et al. 2017).

Dentre os fatores que interferem no processo de propagação vegetativa pode ser destacado o tamanho do recipiente para produção de mudas. Nesse sentido, estudos devem ser realizados para que o recipiente permita o desenvolvimento radicial de forma adequada, para suporte e acondicionamento da miniestaca até seu desenvolvimento e estabelecimento como muda. $\mathrm{O}$ uso de recipientes inadequados é uma das causas mais comuns da malformação do sistema radicular ou radicial de mudas em viveiro, por promover distribuição anormal de raízes laterais, ocasionando o desequilíbrio na absorção de água e nutrientes para atender às necessidades da planta (MAFIA et al., 2005).

Com base na escassez de estudos científicos referentes à propagação vegetativa da espécie em questão, objetivou-se avaliar o enraizamento de miniestacas de Croton urucurana Baill., confeccionadas a partir de diferentes posições do ramo na planta matriz e diferentes recipientes.

\section{MATERIAL E MÉTODO}

O experimento foi desenvolvido no período de setembro a outubro de 2018, no viveiro de produção de mudas do Instituto Federal de Educação, Ciências e Tecnologia de Mato Grosso Campus São Vicente, Centro de Referência de Campo Verde, localizado no município de Campo Verde - MT, cujas coordenadas geográficas aproximadas são $55^{\circ} 10^{\prime} 08^{\prime \prime} \mathrm{W}$ e $15^{\circ} 32^{\prime} 48^{\prime \prime} \mathrm{S}$, e altitude de $736 \mathrm{~m}$.

O minijardim clonal foi constituído de minicepas, obtidas pela propagação seminífera de propágulos de sangra-d'água advindo da técnica de "resgate de mudas", em área de vegetação nativa às margens de uma estrada vicinal, no Assentamento Santo Antônio da Fartura, município de Campo Verde/MT, em junho de 2017. Na coleta de mudas utilizaram-se "mini pás de jardim", e acondicionaram-se as mudas em caixas plásticas com areia umedecida, para transporte até o viveiro.

No viveiro, as mudas foram plantadas em bandejas de polietileno de 50 células/bandeja, tendo cada célula capacidade para $100 \mathrm{~cm}^{3}$, preenchidas com o substrato comercial Vivatto ${ }^{\circledR}$. Quando atingiram altura média de $16 \mathrm{~cm}$ (com 85 dias em viveiro), as mudas (minicepas) foram transferidas para o minijardim clonal. Aos 45 dias após a implantação do minijardim clonal, houve poda dos ápices à uma altura média de $20 \mathrm{~cm}$ da base, com intuito da formação de brotações juvenis para coleta de miniestacas. 
O minijardim clonal foi estabelecido em sistema semi-hidrôponico utilizando dois canteiros suspensos, sob cobertura de plástico transparente de polietileno, sendo os canaletões compostos por calhas de cimento-amianto, com 9,0 $\mathrm{m}$ de comprimento, 0,8 $\mathrm{m}$ de largura e 0,20 m de profundidade, no fundo preenchido com uma camada de pedra brita $\left(\mathrm{n}^{\mathrm{o}} 2\right)$ e completados com areia de textura de grossa até a superfície. O minijardim foi constituído por 210 minicepas, alocadas no espaçamento de $0,25 \mathrm{~m}$ x $0,25 \mathrm{~m}$, com fertirrigação por gotejamento distribuída três vezes ao dia, em uma vazão total diária de $4 \mathrm{~L} \mathrm{~m}^{-2}$. A solução nutritiva utilizada na fertirrigação foi constituída pelas seguintes concentrações dos sais: nitrato de cálcio $\left(0,920 \mathrm{~g} \mathrm{~L}^{-1}\right)$, cloreto de potássio $\left(0,240 \mathrm{~g} \mathrm{~L}^{-1}\right)$, nitrato de potássio $\left(0,140 \mathrm{~g} \mathrm{~L}^{-1}\right)$, monoamônio fosfato $\left(0,096 \mathrm{~g} \mathrm{~L}^{-1}\right)$, sulfato de magnésio $\left(0,364 \mathrm{~g} \mathrm{~L}^{-1}\right)$, hidroferro $\left(0,040 \mathrm{~g} \mathrm{~L}^{-1}\right)$, ácido bórico $\left(2,800 \mathrm{mg} \mathrm{L}^{-1}\right)$, sulfato de zinco $\left(0,480 \mathrm{mg} \mathrm{L}^{-1}\right)$, sulfato de manganês $\left(1,120 \mathrm{mg} \mathrm{L}^{-1}\right)$, sulfato de cobre $\left(0,100 \mathrm{mg} \mathrm{L}^{-1}\right)$ e molibdato de sódio $\left(0,040 \mathrm{mg} \mathrm{L}^{-1}\right)$. A condutividade elétrica e o $\mathrm{pH}$ da solução nutritiva não foram controladas, pois substituía-se a solução nutritiva semanalmente.

Os tratamentos foram arranjados em esquema fatorial $2 \times 3$, sendo dois tipos de recipientes (recipientes de $55 \mathrm{~cm}^{3}$ e $110 \mathrm{~cm}^{3}$ ) e três tipos de miniestacas em relação a posição no ramo da planta matriz (apicais, semilenhosas e lenhosas). O delineamento utilizado foi o de blocos ao acaso, com 4 repetições. As parcelas foram compostas por 16 miniestacas.

As miniestacas foram confeccionadas com um corte em bisel na base e corte reto na parte superior, com aproximadamente $10 \mathrm{~cm}$ de comprimento, e mantidas com duas folhas reduzidas em cerca de $50 \%$ de sua área. Após serem preparadas, a metade inferior das miniestacas foram inseridas no substrato à base de casca de arroz carbonizada + vermiculita (1:1) e acondicionadas em recipientes com diferentes capacidades $\left(55 \mathrm{~cm}^{3}\right.$ e $\left.110 \mathrm{~cm}^{3}\right)$. Após o estaqueamento, os recipientes contendo as miniestacas foram transferidos para a casa de vegetação com umidade relativa do ar superior a $80 \%$, sob sistema de nebulização intermitente, e cobertura plástica de polipropileno e sombrite (50\%). As miniestacas permaneceram nessas condições por 25 dias e, posteriormente, foram transferidas para casa de sombra (sombreamento de 50\%) por 10 dias, com nebulização.

Na saída da casa de vegetação (25 dias após a instalação do experimento) e casa de sombra (35 dias após a instalação do experimento) foram avaliadas as seguintes variáveis, em porcentagem: enraizamento (PE), considerando a exposição de raízes no fundo do tubete, sobrevivência (PS) - composta por miniestacas vivas e não enraizadas, brotação (PB) e manutenção de folhas (PMF). 
Os dados foram submetidos a análise de variância (Teste F) e as médias dos níveis de cada fator foram comparadas pelo teste de Tukey a $5 \%$ e $1 \%$ de probabilidade, por meio do programa computacional ASSISTAT (SILVA; AZEVEDO, 2016).

\section{RESULTADO E DISCUSSÃO}

Analisando os dados obtidos das miniestacas na saída da casa de vegetação, observou-se interação significativa entre os fatores apenas para porcentagem de manutenção de folhas, sendo constatado o efeito significativo do volume do recipiente na variável porcentagem de sobrevivência e do tipo de miniestaca na porcentagem de enraizamento, sobrevivência e brotação (Tabela 1).

Tabela 1. Resumo da análise de variância para porcentagens de enraizamento (PE), sobrevivência (PS), brotação (PB) e manutenção de folhas (PMF) em miniestacas de sangrad'água na saída da casa de vegetação. Campo Verde - MT, 2018.

\begin{tabular}{|c|c|c|c|c|c|}
\hline \multirow{2}{*}{ Fontes de variação } & \multirow{2}{*}{ GL } & \multicolumn{4}{|c|}{ Quadrados Médios } \\
\hline & & PE & PS & $\mathrm{PB}$ & PMF \\
\hline Recipiente (A) & 1 & $1.100,76^{\mathrm{ns}}$ & $1.368,06^{* *}$ & $651,56^{\mathrm{ns}}$ & $1.881,51^{*}$ \\
\hline Tipo de miniestaca (B) & 2 & $1.398,11 *$ & $957,66^{* *}$ & $11.720,73 * *$ & $4.983,09 * *$ \\
\hline Interação (A x B) & 2 & $441,08^{\mathrm{ns}}$ & $103,96^{\mathrm{ns}}$ & $812,03^{\mathrm{ns}}$ & $1.564,13^{*}$ \\
\hline Erro & 18 & 262,59 & 122,16 & 289,74 & 283,31 \\
\hline Total & 23 & - & - & - & - \\
\hline Coeficiente de variação (\%) & & 20,0 & 74,5 & 30,5 & 22,6 \\
\hline
\end{tabular}

Constatou-se maior sobrevivência de miniestacas no recipiente de $55 \mathrm{~cm}^{3}(22,4 \%)$, diferindo estatisticamente dos resultados obtidos quando se utilizaram recipiente de $110 \mathrm{~cm}^{3}$ $(7,3 \%)$ (Tabela 2), sendo que sobrevivência diz respeito as miniestacas que se mantiveram vivas, mas não enraizaram. A sobrevivência diz respeito as miniestacas que se mantiveram vivas, mas não enraizaram, inversamente correlata com a porcentagem de miniestacas enraizadas. A condição ambiental do substrato necessária para o metabolismo da miniestaca, pode ser obtida utilizando-se recipientes maiores. Recipiente de $100 \mathrm{~cm}^{3}$ foram considerados adequados para a sobrevivência de cedro-rosa (Cedrela fissilis Vell.) (ANTONIAZZI et al., 2013). 
Tabela 2. Comparação de médias para porcentagem sobrevivência de miniestacas de sangrad'água, em dois recipientes, na saída da casa de vegetação. Campo Verde - MT, 2018.

\begin{tabular}{cc}
\hline Recipiente & Sobrevivência $(\%)$ \\
\hline $55 \mathrm{~cm}^{3}$ & $22,4 \mathrm{a}$ \\
$110 \mathrm{~cm}^{3}$ & $7,3 \mathrm{~b}$ \\
\hline
\end{tabular}

Médias seguidas de mesma letra na coluna não diferem entre si pelo teste de Tukey, a 1\% de probabilidade.

Fonte: Elaborado pelo Autor, 2018.

Quanto considerado o tipo de miniestaca, observou-se que aquelas de origem apical resultam em melhor enraizamento (91,5\%) quando comparadas às miniestacas lenhosas $(65,6 \%)$, embora não tenha diferido estatisticamente das miniestacas semilenhosas (83,6\%) (Tabela 3). Esse resultado se devem ao fato de que miniestacas apicais possuem meristemas, que facilitam o enraizamento e, por isso, são as mais usadas em viveiros florestais (HARTMANN et al. 2017). Já miniestacas oriundas das posições semilenhosa e lenhosa do ramo apresentam perda de vigor, devido a lignificação dos tecidos e os efeitos negativos do envelhecimento ontogenético (WENDLING; XAVIER, 2001).

Em relação à sobrevivência, foram constatados $27,4 \%$ de miniestacas lenhosas vivas, diferindo estatisticamente das miniestacas de origem semilenhosa $(10,1 \%)$ e apical $(7,1 \%)$ (Tabela 3). Quando considerado apenas as miniestacas apicais e semilenhosas de progênies de angico-vermelho (Anadenanthera macrocarpa (Benth.) Brenan.), não constataram diferença estatística na variável sobrevivência, sobre os tipos de miniestacas (apical e semilenhosa), na saída da casa de vegetação e casa de sombra (DIAS et al., 2015). Nesse sentido, Ferreira et al. (2012) estudando os mesmos tipos de miniestacas não obtiveram diferença estatística para sobrevivência de miniestacas de cedro australiano (Toona ciliata M. Roem var. australis (F. Muell.) Bahadur) em casa de vegetação.

As miniestacas de onde se constataram as maiores porcentagens de brotação foram aquelas de origem semilenhosa $(81,3 \%)$ e lenhosa $(74,2 \%)$, que não diferiram entre si, mas diferiram do resultado encontrado nas miniestacas de origem apical $(11,2 \%)$ (Tabela 3). Nota-se que em miniestacas apicais o enraizamento foi de $91,5 \%$ com brotação apenas de 11,2\%, ao passo que apenas $65,6 \%$ das miniestacas lenhosas apresentaram enraizamento, mas 74,2\% delas estavam brotadas. Com isso, pode ter havido a mobilização competitiva ou equacionada na distribuição das reservas, tanto para a formação de raízes quanto para a formação de parte aérea. 
Tabela 3. Comparação de médias para porcentagem de enraizamento, sobrevivência e brotação em três tipos de miniestacas de sangra-d'água, na saída da casa de vegetação. Campo Verde MT, 2018.

\begin{tabular}{cccc}
\hline Tipo de miniestaca & Enraizamento $(\%)^{*}$ & Sobrevivência $(\%)^{* *}$ & Brotação $(\%)^{* *}$ \\
\hline Apical & $91,5 \mathrm{a}$ & $7,1 \mathrm{~b}$ & $11,2 \mathrm{~b}$ \\
Semilenhosa & $83,6 \mathrm{ab}$ & $10,1 \mathrm{~b}$ & $81,3 \mathrm{a}$ \\
Lenhosa & $65,6 \mathrm{~b}$ & $27,4 \mathrm{a}$ & $74,2 \mathrm{a}$ \\
\hline
\end{tabular}

Médias seguidas de mesma letra na coluna não diferem entre si pelo teste de Tukey, a *5\% e $* * 1 \%$ de probabilidade.

Fonte: Elaborado pelo Autor, 2018.

Na porcentagem de manutenção de folhas na saída da casa de vegetação, no recipiente de $55 \mathrm{~cm}^{3}$, observa-se que a miniestaca de origem apical e semilenhosa apresentam as maiores e iguais porcentagens (87,5\%), diferindo-as estatisticamente da lenhosa (21,9\%) (Tabela 4). Quando acondicionado no recipiente de $110 \mathrm{~cm}^{3}$, as miniestacas apical (98,5\%), semilenhosa $(81,3 \%)$ e lenhosa $(70,3 \%)$, não apresentaram diferença estatística entre si. Nota-se que as miniestacas mantiveram suas folhas originais, desde o início do experimento, com exceção das lenhosas alojadas sobre recipientes de $55 \mathrm{~cm}^{3}$ (21,9\%), que foi inferior à todas as demais combinações entre recipiente e tipo de estaca (Tabela 4). Recipiente menor $\left(55 \mathrm{~cm}^{3}\right)$, pode ocasionar em menor armazenamento de água e, associado ao maior envelhecimento dos tecidos das miniestacas lenhosas, pode ter comprometido a manutenção das folhas para esse tipo de miniestaca, conforme relatado por Wendling e Xavier (2001), com efeito similar ao ocorrido no enraizamento.

Tabela 4. Comparação de médias para porcentagem de manutenção de folhas de sangra-d'água, em dois recipientes e três tipos de miniestacas, na saída da casa de vegetação. Campo Verde MT, 2018.

\begin{tabular}{cccc}
\hline \multirow{2}{*}{ Recipiente } & \multicolumn{3}{c}{ Tipo de miniestaca } \\
\cline { 2 - 4 } & Apical (\%) & Semilenhosa (\%) & Lenhosa (\%) \\
\hline $55 \mathrm{~cm}^{3}$ & $87,5 \mathrm{aA}$ & $87,5 \mathrm{aA}$ & $21,9 \mathrm{bB}$ \\
$110 \mathrm{~cm}^{3}$ & $98,5 \mathrm{aA}$ & $81,3 \mathrm{aA}$ & $70,3 \mathrm{aA}$ \\
\hline
\end{tabular}

Médias seguidas da mesma letra, minúscula na coluna e maiúscula na linha, não diferem entre si pelo teste de Tukey, a $5 \%$ de probabilidade.

Fonte: Elaborado pelo Autor, 2018.

Após o período de permanência em casa de sombra, constatou-se comportamento semelhante àqueles verificados na saída da casa de vegetação, com interação significativa entre os fatores apenas para porcentagem de manutenção de folhas, sendo constatado o efeito significativo do recipiente na variável porcentagem de sobrevivência e do tipo de miniestaca nas variáveis porcentagem enraizamento, sobrevivência e brotação (Tabela 5). 
Tabela 5. Resumo da análise de variância para porcentagens de enraizamento (PE), sobrevivência (PS), brotação (PB) e manutenção de folhas (PMF) em miniestacas de sangrad'água na saída da casa de sombra. Campo Verde - MT, 2018.

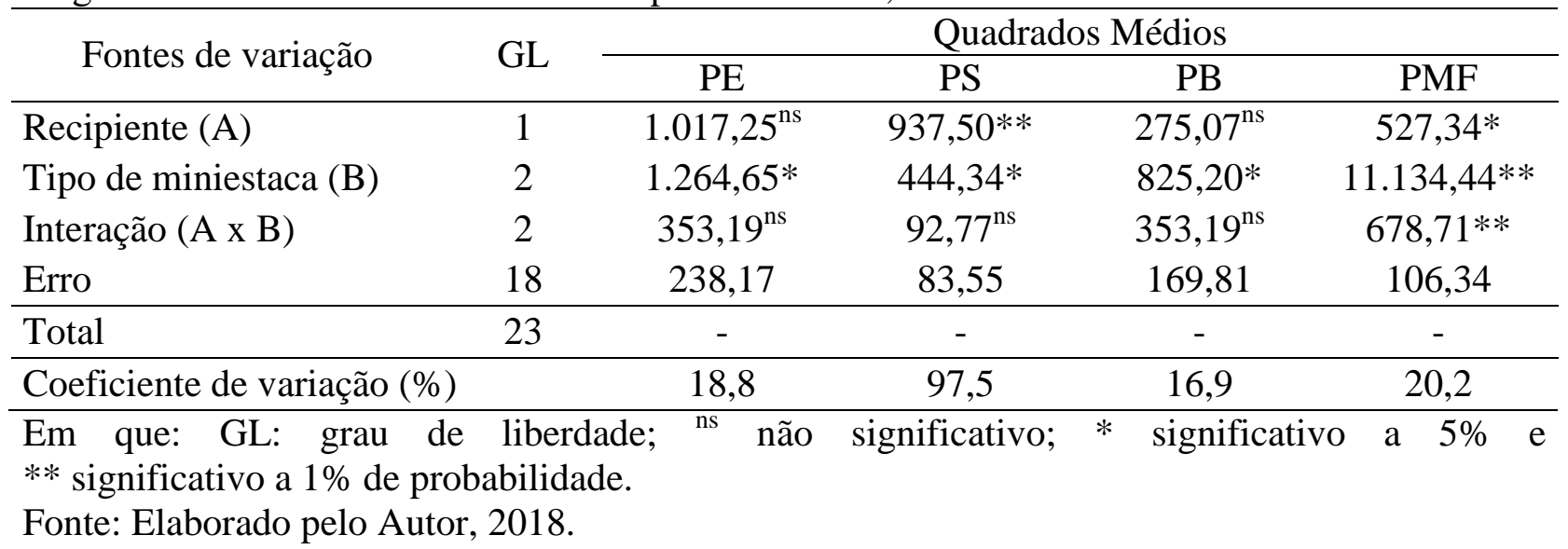

A sobrevivência foi de $15,6 \%$ para miniestacas mantidas em recipientes de $55 \mathrm{~cm}^{3}$ e de apenas $3,1 \%$ para as miniestacas que foram alojadas em recipientes de $110 \mathrm{~cm}^{3}$, diferindo entre si e demonstrando a melhor sobrevivência quando acondicionadas no menor recipiente $\left(55 \mathrm{~cm}^{3}\right)$ (Tabela 6$)$.

Tabela 6. Comparação de médias para porcentagem de sobrevivência de miniestacas de sangrad'água, em dois recipientes, na saída da casa de sombra. Campo Verde - MT, 2018.

\begin{tabular}{cc}
\hline Recipiente & Sobrevivência $(\%)$ \\
\hline $55 \mathrm{~cm}^{3}$ & $15,6 \mathrm{a}$ \\
$110 \mathrm{~cm}^{3}$ & $3,1 \mathrm{~b}$ \\
\hline
\end{tabular}

Médias seguidas de mesma letra na coluna não diferem entre si pelo teste de Tukey, a $1 \%$ de probabilidade.

Fonte: Elaborado pelo Autor, 2018.

Sobre ao enraizamento, observou-se que aquelas de origem apical resultam em melhor enraizamento $(92,2 \%)$ quando comparadas às miniestacas lenhosas $(68,0 \%)$, embora não tenha diferido estatisticamente das miniestacas semilenhosas (86,0\%) (Tabela 7). Miniestacas lenhosas têm seu vigor diminuído em função do envelhecimento ontogênico (WENDLING; XAVIER, 2001), necessitando de desdiferenciação celular previamente à formação de raízes. Provavelmente, as atividades metabólicas necessárias ao enraizamento em miniestacas lenhosas exigem melhor condição ambiental do substrato. Benin et al. (2013), obtiveram enraizamento com a miniestaca de origem apical superior a semilenhosa e lenhosa, que não diferiram entre si, utilizando o Eucalyptus benthamii, avaliado aos 90 dias em pleno sol.

$\mathrm{Na}$ sobrevivência das miniestacas, observa-se $18,0 \%$ de miniestacas de origem lenhosas vivas, diferindo estatisticamente da apical $(5,5 \%)$ e semilenhosa (4,7\%) (Tabela 7). Considerando que a sobrevivência avalia as miniestacas vivas, porém não enraizadas, acredita-se que o Nucleus, v.17, n.2, out.2020 
envelhecimento ontogênico das miniestacas lenhosas tenha impedido a formação de raízes ou demandado maior tempo para o enraizamento, não considerado nessa pesquisa. O tipo e posição do propágulo retirado da planta matriz, influencia no enraizamento e sobrevivência das miniestacas (FERREIRA et al., 2012). Conforme estudos de Franzon et al. (2004), estacas de origem lenhosa apresentaram maior porcentagem de sobrevivência quando comparada às miniestacas semilenhosas e apicais de goiabeira-serrana (Acca sellowiana Berg) avaliadas após 60 dias em casa de vegetação.

As miniestacas semilenhosa $(87,5 \%)$ e lenhosa $(77,4 \%)$, foram as que obtiveram maiores porcentagens de brotação, que não diferiram entre si, mas diferiram do resultado encontrado na de origem apical $(67,2 \%)$ (Tabela 7$)$. Normalmente, as miniestacas utilizam suas reservas para fomentar com carbono e energia a biossíntese de ácidos nucléicos, proteínas e outras substâncias essenciais à formação dos primórdios radiciais (LIMA et al., 2011).

Tabela 7. Comparação de médias para porcentagem de enraizamento, sobrevivência e brotação em três tipos de miniestacas de sangra-d'água, na saída da casa de sombra. Campo Verde - MT, 2018.

\begin{tabular}{cccc}
\hline Tipo de miniestaca & Enraizamento $(\%)$ & Sobrevivência $(\%)$ & Brotação $(\%)$ \\
\hline Apical & $92,2 \mathrm{a}$ & $5,5 \mathrm{~b}$ & $67,2 \mathrm{~b}$ \\
Semilenhosa & $86,0 \mathrm{ab}$ & $4,7 \mathrm{~b}$ & $87,5 \mathrm{a}$ \\
Lenhosa & $68,0 \mathrm{~b}$ & $18,0 \mathrm{a}$ & $77,4 \mathrm{ab}$ \\
\hline
\end{tabular}

Médias seguidas de mesma letra na coluna não diferem entre si pelo teste de Tukey, a 5\% de probabilidade.

Fonte: Elaborado pelo Autor, 2018.

Na porcentagem de manutenção de folhas na saída da casa de sombra, no recipiente de 55 $\mathrm{cm}^{3}$, observa-se que a miniestaca de origem apical $(73,4 \%)$ e semilenhosa $(60,9 \%)$ apresentam as maiores porcentagens, diferindo-as estatisticamente da lenhosa (4,7\%) (Tabela 4). Quando acondicionado no recipiente de $110 \mathrm{~cm}^{3}$, as miniestacas apical $(98,4 \%)$, semilenhosa $(50,0 \%)$ e lenhosa (18,8\%), apresentaram diferença estatística entre si. Quanto a manutenção de folhas, o volume do recipiente e o tipo de miniestaca são dependentes, onde miniestacas lenhosas acondicionadas em recipientes de 55 e $110 \mathrm{~cm}^{3}$ (4,7 e 18,8\%, respectivamente) de substrato perdem mais folhas (Tabela 8).

Isso provavelmente está associado à disponibilidade hídrica para a miniestacas bem como ao grau de lignificação de seus tecidos. Ainda, é possível inferir que a perda da folha não resultou em translocação de suas reservas para o enraizamento haja vista que miniestacas lenhosas foram as que menos enraizaram quando comparadas as miniestacas apicais. Por outro lado, como as folhas são locais de síntese de auxina e carboidratos, seria de se esperar que a retenção foliar favorecesse a sobrevivência e a formação radicial (PACHECO; FRANCO, 2008). 
Tabela 8. Comparação de médias para porcentagem de manutenção de folhas em miniestacas de sangra-d'água, em dois recipientes e três tipos de miniestacas, na saída da casa de sombra. Campo Verde - MT, 2018.

\begin{tabular}{cccc}
\hline \multirow{2}{*}{ Recipiente } & \multicolumn{3}{c}{ Tipo de miniestaca } \\
\cline { 2 - 4 } & Apical (\%) & Semilenhosa (\%) & Lenhosa (\%) \\
\hline $55 \mathrm{~cm}^{3}$ & $73,4 \mathrm{bA}$ & $60,9 \mathrm{aA}$ & $4,7 \mathrm{aB}$ \\
$110 \mathrm{~cm}^{3}$ & $98,4 \mathrm{aA}$ & $50,0 \mathrm{aB}$ & $18,8 \mathrm{aC}$ \\
\hline
\end{tabular}

Médias seguidas da mesma letra, minúscula na coluna e maiúscula na linha, não diferem entre si pelo teste de Tukey, a $1 \%$ de probabilidade.

Fonte: Elaborado pelo Autor, 2018.

Embora as miniestacas apicais tenham apresentado maior enraizamento que as miniestacas lenhosas, é importante salientar o bom enraizamento obtido para a espécie, uma vez que o menor enraizamento obtido foi de $68,0 \%$ na miniestaca de origem lenhosa na saída da casa de sombra para a possível inserção a pleno sol. Isso se deve, provavelmente ao fato que as plantas matrizes eram minicepas, cultivadas em sistema semi-hidropônico e com bom equilíbrio nutricional, o que faz da técnica de miniestaquia uma forma de propagação vegetativo muito eficiente. Desta forma, e com base nos resultados obtidos nos testes realizados entende-se que a espécie em estudo é uma planta de fácil enraizamento, conforme a classificação de Hartmann et al. (2017).

\section{CONCLUSÃO}

Confeccionar miniestacas das partes apical e semilenhosa do ramo da planta matriz otimiza o enraizamento;

Podem ser utilizados recipientes de $55 \mathrm{~cm}^{3}$ ou de $110 \mathrm{~cm}^{3}$ para a propagação vegetativa de Croton urucurana por miniestaquia.

\section{REFERÊNCIAS}

ALFENAS, A. C. et al. Clonagem e doenças do Eucalipto. 2. ed. Viçosa: UFV, 2009.

ANTONIAZZI, A. P. et al. Eficiência de recipientes no desenvolvimento de mudas de Cedrela fissilis Vell. (Meliaceae). Revista Brasileira de Biociências, v. 11, n. 3, p. 313-317, 2013.

BENIN, C. C.; PERES, F. S. B.; GARCIA, F. A. O. Enraizamento de miniestacas apicais, intermediárias e basais em clones de Eucalyptus benthamii. Floresta, v. 43, n. 3, p. 421-428, 2013.

CAMILLO, J.; VIEIRA, R. F. Croton urucurana - Sangra-d'água. In: VIEIRA, R. FONTES; CAMILLO, J.; CORADIN, L. (Eds.). Espécies nativas da flora brasileira de valor econômico atual ou potencial: plantas para o futuro - região Centro-oeste. Brasília - DF: MMA, 2016. p. 753-760. 
DIAS, P. C. et al. Propagação vegetativa de Schizolobium amazonicum por estaquia. Cerne, v. 21, n. 3, p. 379-386, 2015.

FACHINELLO, J. C.; HOFFMANN, A.; NACHTIGAL, J. C. (ED.). Propagação de plantas frutíferas. Brasília: Embrapa Informação Tecnológica; Bento Gonçalves: Embrapa Uva e Vinho, 2005.

FERREIRA, D. A. et al. Influência da posição das miniestacas na qualidade de mudas de cedro australiano e no seu desempenho inicial no pós-plantio. Ciência Florestal, v. 22, n. 4, p. 715723, 2012.

FRANZON, R. C.; ANTUNES, L. E. C.; RASEIRA, M. C. B. Efeito do aib e de diferentes tipos de estaca na propagação vegetativa da goiabeira-serrana (Acca sellowiana Berg). Revista Brasileira Agrociência, v. 10, n. 4, p. 515-518, 2004.

HARTMANN, H. T. et al. Hartmann \& Kester's plant propagation: principles and practices. 9. ed. London: Pearson, 2017.

LIMA, D. M. et al. Capacidade de enraizamento de estacas de Maytenus muelleri Schwacke com a aplicação de ácido indol butírico relacionada aos aspectos anatômicos. Revista Brasileira de Plantas Medicinais, v. 13, n. 4, p. 422-438, 2011.

LORENZI, H. Árvores brasileiras manual de identificação e cultivo de plantas arbóreas nativas do Brasil (vol.1). 7. ed. Nova Odessa: Instituto Plantarum, 2016.

MAFIA, R. G. et al. Critério técnico para determinação da idade ótima de mudas de eucalipto para plantio. Revista Árvore, v. 29, n. 6, p. 947-953, 2005.

PACHECO, J. P.; FRANCO, E. T. H. Substratos e estacas com e sem folhas no enraizamento de Luehea divaricata Mart. Ciência Rural, v. 38, n. 7, p. 1900-1906, 2008.

SCALON, S. P. Q. et al. Crescimento inicial de mudas de sangra-d'água (Croton urucurana Baill.) sob sombreamento e aplicação de giberelina. Revista Brasileira de Plantas Medicinais, v. 10, n. 3, p. 61-66, 2008.

SILVA, F. A. S. E; AZEVEDO, C. A. V. The Assistat Software Version 7.7 and its use in the analysis of experimental data. African Journal of Agricultural Research, v. 11, n. 39, p. 37333740, 2016.

SODRÉ, R. C.; SILVA, M. J. O gênero Croton L. (Euphorbiaceae s.s. - Crotonoideae) na Floresta Nacional de Silvânia, Goiás, Brasil. Iheringia, v. 70, n. 1, p. 89-104, 2015.

SOLDERA, C. C.; ZANELLA, G. N.; FRASSON, A. P. Z. Avaliação da atividade antibacteriana de Croton urucurana. Revista Contexto \& Saúde, v. 10, n. 19, p. 25-31, 2010.

SOUZA, V. C.; LORENZI, H. Botânica Sistemática - Guia ilustrado para identificação das famílias de Fanerógamas nativa e exóticas no Brasil, baseado em APG III. Nova Odessa: Instituto Plantarum, 2012.

WENDLING, I.; FERRARI, M. P.; GROSSI, F. Curso intensivo de viveiros e produção de mudas. 2002. 
WENDLING, I.; XAVIER, A. Gradiente de maturação e rejuvenescimento aplicado em espécies florestais. Floresta e Ambiente, v. 8, n. 1, p. 187-194, 2001.

XAVIER, A.; WENDLING, I.; SILVA, R. L. Silvicultura clonal princípios e técnicas. 2. ed. Viçosa: UFV, 2013. 